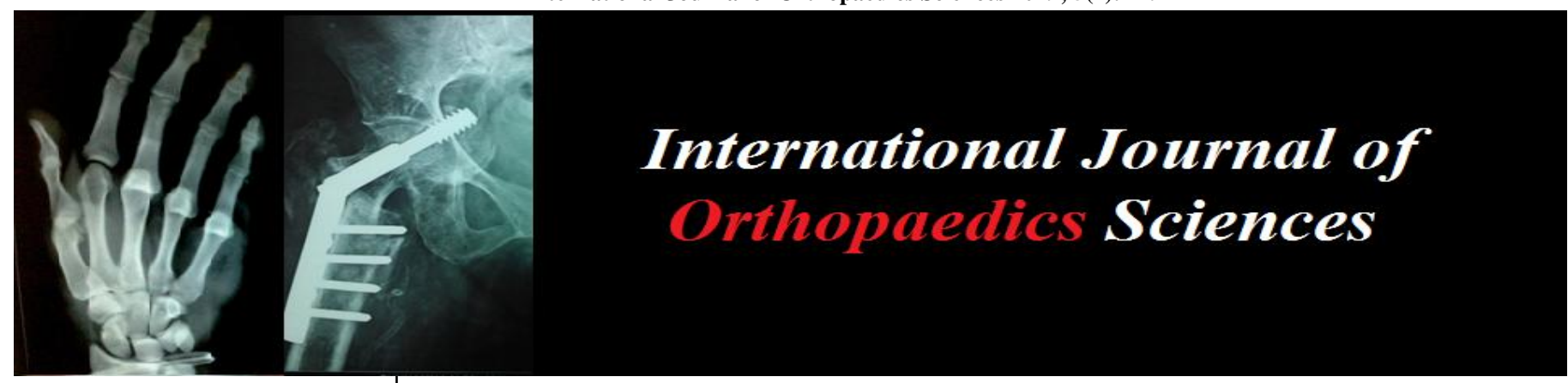

ISSN: $2395-1958$

IJOS 2019; 5(2): 219-222

(C) 2019 IJOS

www.orthopaper.com

Received: 04-02-2019

Accepted: 07-03-2019

Dr. Rajesh K Ambulgekar Proff and Hod, Deptt. of Orthopaedics, Dr. Shankarrao Chavan Government Medical College, Nanded, Maharashtra, India

Dr. Shahbaz Hasan

Resident Deptt. of Orthopaedics,

Dr. Shankarrao Chavan

Government Medical College,

Nanded, Maharashtra, India

Dr. Vishal Gurnani

Resident Deptt. of Orthopaedics, Dr. Shankarrao Chavan

Government Medical College,

Nanded, Maharashtra, India
Correspondence

Dr. Shahbaz Hasan

Resident Deptt. of Orthopaedics,

Dr. Shankarrao Chavan

Government Medical College,

Nanded, Maharashtra, India

\section{Glomus tumour of distal phalynx of hand - A case report}

\section{Dr. Rajesh K Ambulgekar, Dr. Shahbaz Hasan and Dr. Vishal Gurnani}

\section{DOI: https://doi.org/10.22271/ortho.2019.v5.i2e.23}

Abstract

Glomus tumours are very rare variety of hand tumour which accounts for around 1 to $5 \%$ of all hand tumours. These tumours are difficult to diagnose early treatment ensures better recovery of patient and immediate relief of symptoms. We are presenting a case of 26 years old female having pain over tip of right hand middle finger which was initially undiagnosed for around two years. We used volar approach for complete excision of tumour and after 8 months of follow up patient is pain free and shows no signs of recurrence.

Keywords: glomus tumour, distal phalanx, surgery, volar approach

\section{Introduction}

Glomus tumour are rare benign hamartoma of vascular origin arising from glomus body. glomus tumour arising from neuromyoarterial glomus which is and arteriovenous anastomosis functioning without an intermediary capillary bed ${ }^{[1-3]}$ glomus tumour account for up to $1-5 \%$ of hand tumours ${ }^{[4]}$. Classic symptoms include spontaneous pain, pain on light touch, and temperature hyperesthesia ${ }^{[5]}$ The diagnosis for glomus tumor are usually based on clinical finding, (fig 3) but may be supported with other modalities, such as ultrasound and magnetic resonance imaging (MRI) ${ }^{[6,7]}$. (Fig 1) Surgical exicision of tumour is most preferred treatment of choice of glomus tumour. We report a case of glomus tumour which was initially missed to diagnose.

\section{Case report}

A 26 years old female presented with 2 year history of progressively pain and tingling sensation on tip of her right middle finger initially the pain was mild so patient had ignored but since last 2 months pain was increased in intensity. Pain increased in cold water and air, and decreased in hot water and compression of finger. There was no any history of trauma or infection on clinical examination there was no any swelling but tenderness was present over distal phalanx of right hand middle finger on palpation. Radiological examination revealed bony erosive lesion on ulnar aspect of distal phalanx of right hand middle finger. (fig 4 and 5) Subsequently Magnetic resonance imaging was performed revealed a focal rounded lesion in nail bed scalloping the dorsal phalanx of middle finger, the routine and serological was within normal limits

\section{Surgical Procedure}

Patient was operated under wrist block in supine position with hand in supination,rubber band of surgical gloves used as a tourniquet and volar approach was used in which incision given at volar aspect of middle finger (fig 6) then tumour is excised completely with scrapping of distal phalynx bone done to ensure complete removal of tumour.(fig 7 and fig 8) The excised mass was sent for histopathological examination (fig 9). All the procedure went uneventful and without any complication postoperative dressing done on second and fifth day.

Histopathological finding showed vascular channels separated by fibrovascular stroma containing glomus cells arranged in nests and aggregates. Glomus cells are arranged around vessels have a small round regular with vesicular nuclei with scanty cytoplasm. (fig 10). Patient shows no signs of recurrence and pain free after 8 months of follow up. 


\section{Discussion}

Glomus tumor is a benign rare condition in which a complete excision usually leads to cure, with low incidence of recurrence. However, this benign condition has an unusually high morbidity to the patient before the correct diagnosis is made. This attests to the difficulty in correctly diagnosing this lesion initially. Although history and carefully performed physical examination and sensitivity to cold significantly narrow the differential diagnosis, the plain radiographs are minimally helpful until the bony erosion occurrs at the later stages of the disease. There are many surgical techniques available in literature for management of this benign tumour. Ekin et al. ${ }^{[8]}$ described opening a window over the nail in case of subungual tumors. In 1994 Tada et al. ${ }^{[9]}$ reported that location of the resected nail piece to its original place following excision was necessary for the prevention of nail deformities with the window technique. However, it is not possible to perform this technique when the window is extended. In another study, Dailiana et al. ${ }^{[11]}$ described that lateral intervention provided a wide area for tumors of the nail bed and submatrix in subungual cases; through this approach, tumors with multiple localizations could be easily detected. Although lateral intervention is appropriate to prevent deformities of the nail bed, the removal of the nail ensures an improved view ${ }^{[10]}$. Here in our case we have used volar approach for excision of tumour. By this approach we are able to completely excise the tumour with no recurrence till now.

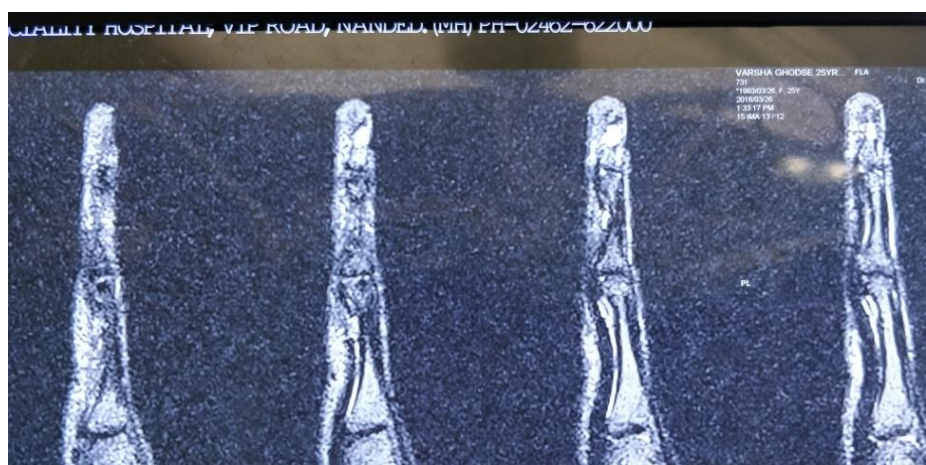

Fig 1.

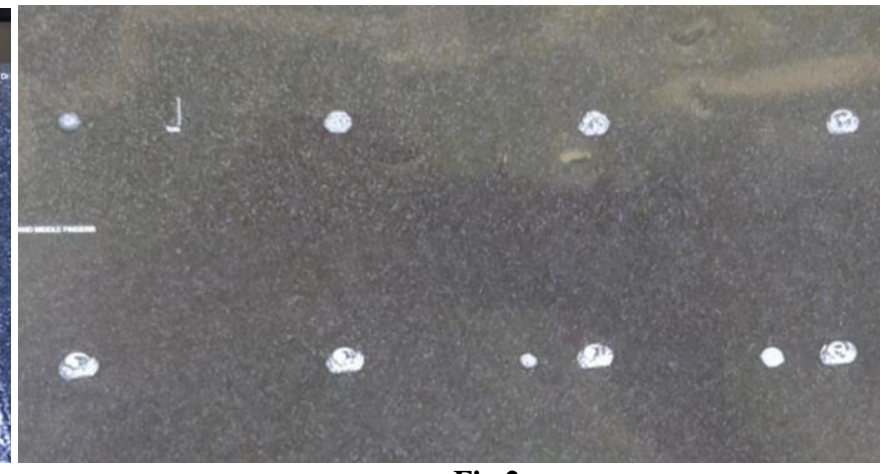

Fig 2.

Fig 1, 2: MRI of right middle finger showing tumour in distal phalanx

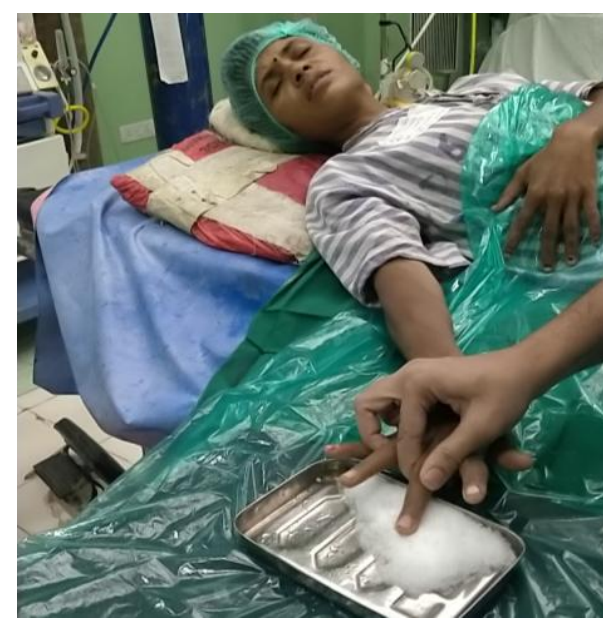

Fig 3: Showing pain on touching ice- the cardinal feature of glomus tumour

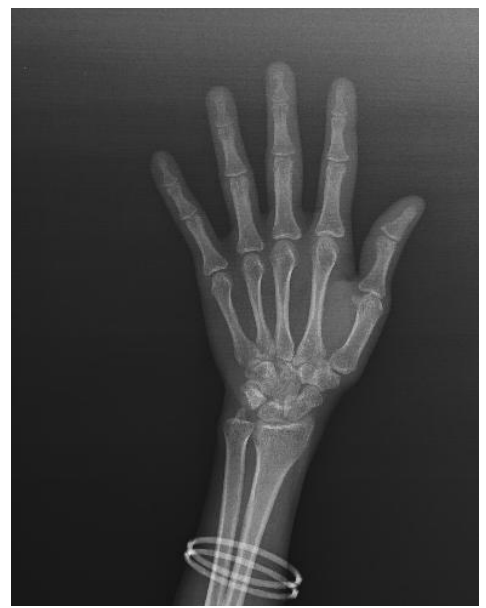

Fig 4: AP and lateral radiograph showing bony erosion at distal phalynx of middle finger

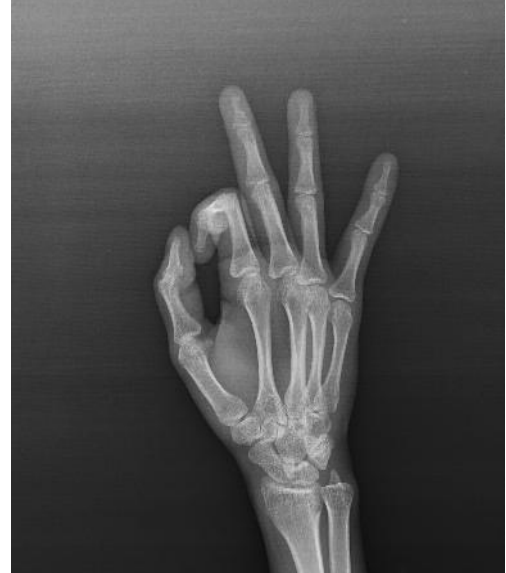

Fig 5: AP and lateral radiograph showing bony erosion at distal phalynx of middle finger

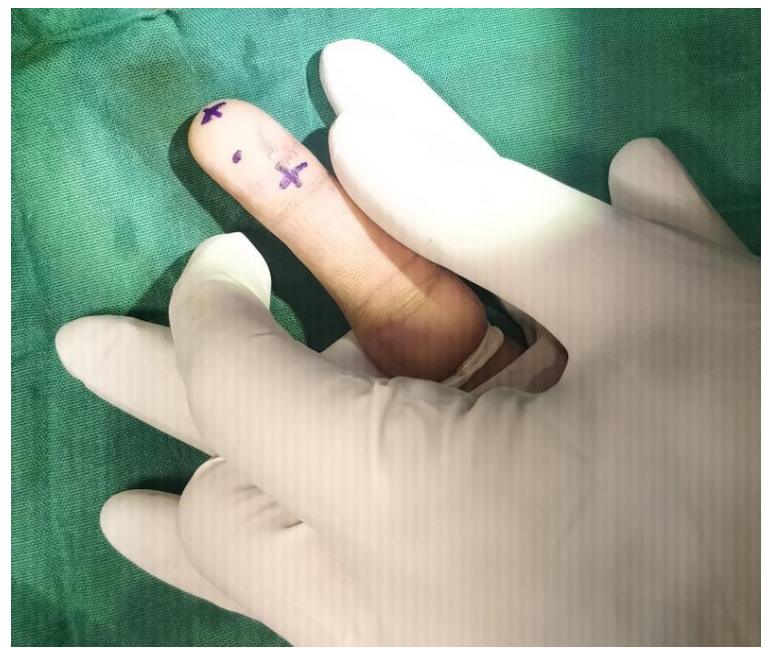

Fig 6: Extent of incision 


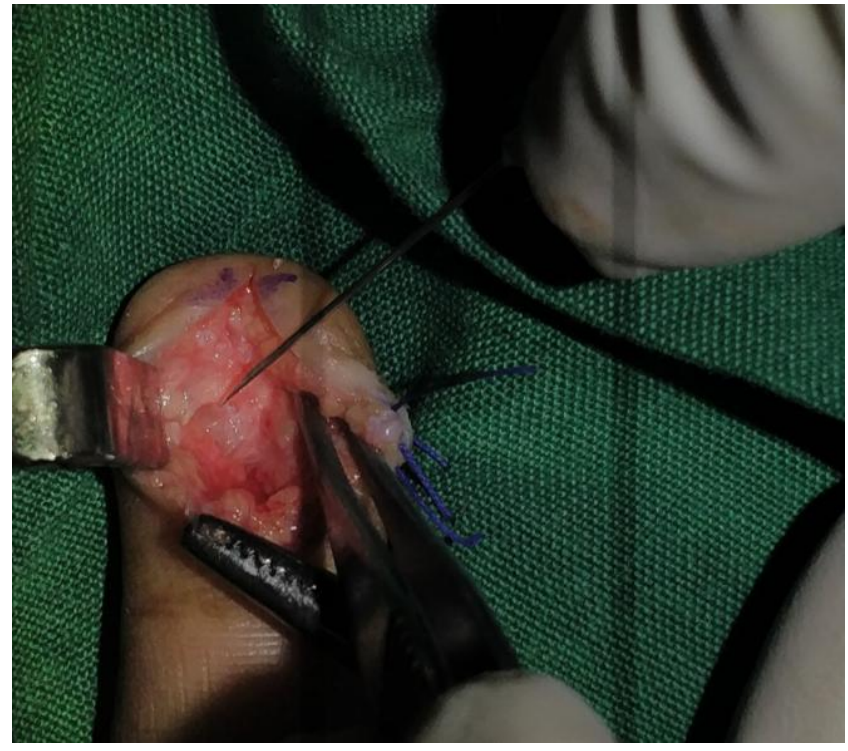

Fig 7: Showing tumour

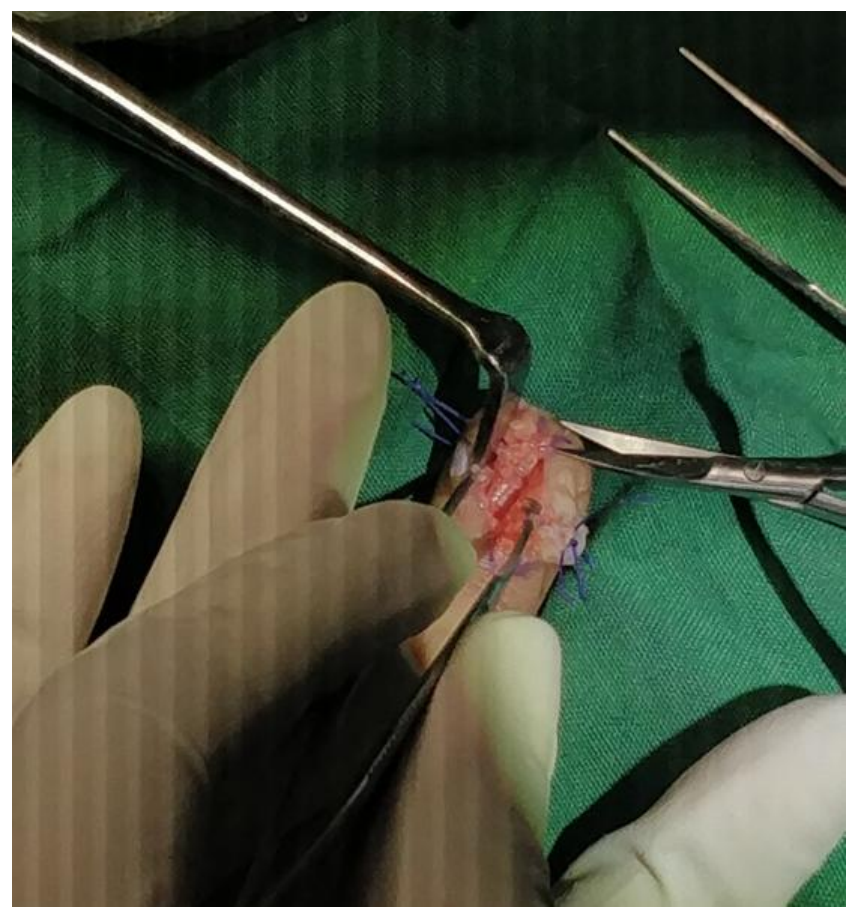

Fig 8: Showing complete removal of tumour, nail bed is visible

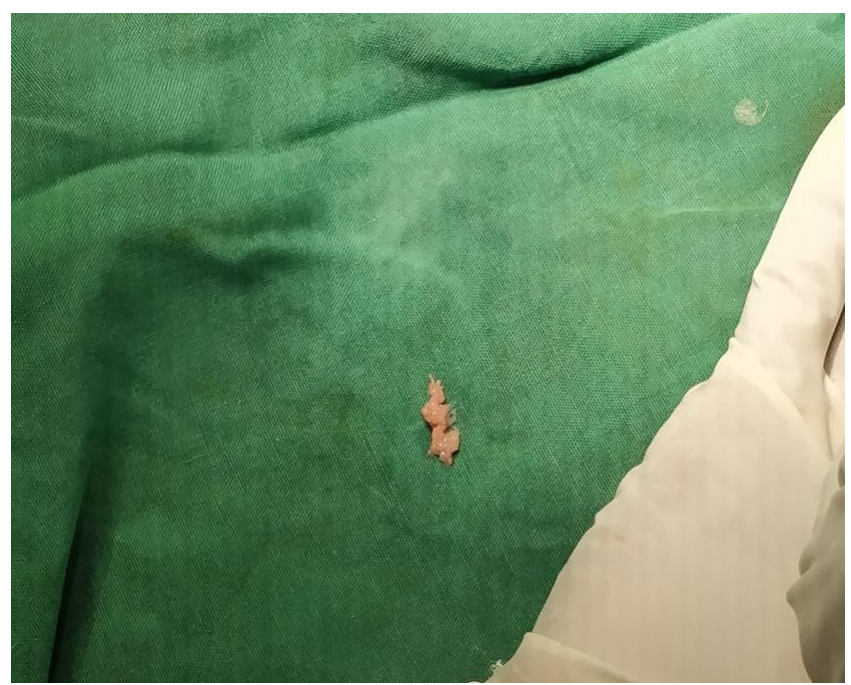

Fig 9: Excised tumour
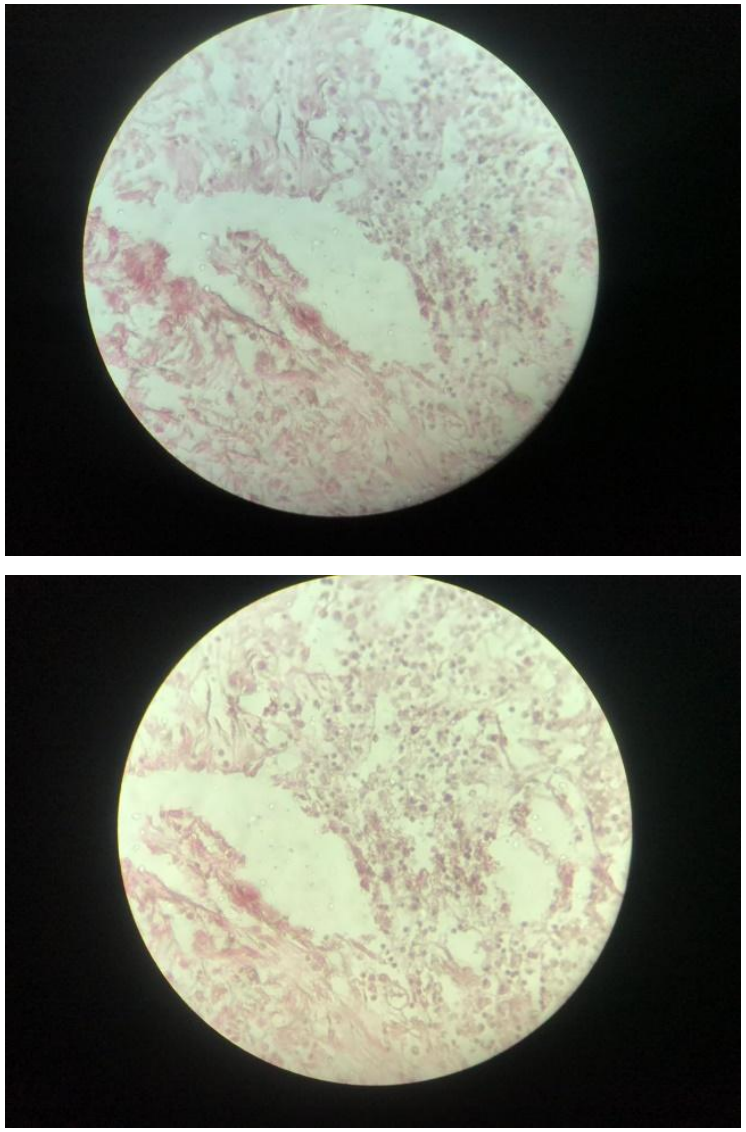

Fig 10: Microscopical view

\section{Conclusion}

Glomus tumour is a rare tumour and diagnosis is often missed as patient does not have any significant complaints except mild Pain. Diagnosis of this uncommon tumour is often clinical and proper localisation of tumour is warranted to further localisation of this tumour and excision of this tumour after diagnosis can prevent patient from severe pain and its psychological effects

\section{References}

1. Carroll RE, Berman AT. Glomus tumors of the hand. Review of the literature and report on twenty-eight cases, J Bone Joint Surg. 1972; 54A:691-703.

2. Drapé JL, Idy-Peretti I, Goettmann S, Guérin-Surville H, Bittoun J. Standard and high resolution magnetic resonance imaging of glomus tumors of toes and fingertips. J Am Acad Dermatol. 1996; 35:550-555.

3. Enzinger FM, Weiss SW. Perivascular tumors. In: Soft tissue tumors. 3rd ed. St. Louis: Mosby; 1995, 701-733.

4. Ugurlar M, Kabakas F, Ugurlar OY, Purisa H, Mer- sa B, Ozcelik IB. Atypically localized glomus tumors. Hand Microsurg 2016; 5: doi:10.5455/hand- microsurg.214790.

5. Song M, Ko HC, Kwon KS, Kim MB. Surgical treatment of subungual glomus tumor: a unique and simple method. Dermatol Surg. 2009; 35(5):786-91.

6. Chen SH, Chen YL, Cheng MH, Yeow KM, Chen HC, Wei FC. The use of ultrasonography in preoperative localization of digital glomus tumors. Plast Reconst Surg. 2003; 112(1):115-9

7. Al-Qattan MM, Al-Namla A, Al-Thunayan A, Al-Subhi F, El- Shayeb AF. Magnetic resonance imaging in the diagnosis of glomus tumours of the hand. J Hand Surg Br. 2005; 30(5):535- 40. 
8. Ekin A, Ozkan M, Kabaklıoglu T. Subungual glo- mus tumours: a different approach to diagnosis and treatment. J Hand Surg Br. 1997; 22:228-9.

9. Tada H, Hirayma T, Takemitsu Y. Prevention of postoperative nail deformity after subungual glomus resection. J Hand Surg Am 1994; 19:500-3.

10. Kabakas F, Ugurlar M, Ozcelik IB, Mersa B, Purisa H. Surgical treatment of subungual glomus tumors: Experience with lateral subperiosteal and transungual approaches. Hand Microsurg. 2016; 5:70-8.

11. Dailiana Z, Pajardi G, Le Viet D, Foucher G. Les tumeurs glomiques de la main: A propos d'une serie de 80 patients. In: Dumontier C, (ed.) L'ongle. Elsevier, Paris. 2000, 201-5. 